\title{
Increase of Innovative Susceptibility of Personnel in Industrial Enterprises
}

\author{
Vitalina Babenko* \\ Department of International \\ E-Commerce and Hotel\&Restaurant \\ Business \\ V.N. Karazin Kharkiv National \\ University \\ Kharkiv, Ukraine \\ vitalinababenko@karazin.ua, \\ http://orcid.org/0000-0002-4816-4579
}

\author{
Oleg Boichenko \\ Department of Organization of \\ Production and Management \\ Organization by a Personnel National \\ Technical University of "Kharkiv \\ Polytechnic Institute" \\ Kharkiv, Ukraine \\ olegmet3000@ukr.net \\ http://orcid.org/0000-0003-2323-4320 \\ Yelyzaveta Koniaieva \\ Department of International Economic \\ Relations \\ V.N. Karazin Kharkiv National \\ University \\ Kharkiv, Ukraine \\ sunnybigday@gmail.com \\ http://orcid.org/0000-0002-2455-7503
}

\author{
Andrii Gusliev \\ Department of International \\ E-Commerce and Hotel\&Restaurant \\ Business \\ V.N. Karazin Kharkiv National \\ University \\ Kharkiv, Ukraine \\ apguslev@gmail.com \\ https://orcid.org/ 0000-0001-9128- \\ $718 \mathrm{X}$
}

\begin{abstract}
In modern conditions of innovative development, the most important resource of production companies and corporations is the innovative susceptibility (IS) of personnel. The key to this is an innovative organization of Human Recourse Management System (HRMS). Accordingly, the task of the study is to analyze the typical HRMS structures of Ukrainian enterprises in comparison with the global ones in order to form an innovative HRMS development strategy and, on this basis, to increase IS of stuff.
\end{abstract}

The goal of this study is to compare the levels of HRMS development in advanced global companies and Ukrainian enterprises in the field of industrial automation. As part of this study, methodological, statistical analysis method of technical and economic characteristics of Ukrainian and world leaders of enterprises in the field of industrial automation are used.

The research methodology consists in processing and disclosing theoretical and methodical units and practical recommendations, which requires the use of innovative personnel using personal industrial enterprises engaged in industrial automation. The HRMS has an impact on personnel, and personnel has an impact on HRMS, without enhancing the personnel IS HRMS will not give positive results from the introduction of innovative innovations in the innovative activities of the IS personnel.

Keywords-innovative susceptibility of personnel, Human Recourse Management System, organizational and management structure, industrial enterprise.

\section{INTRODUCTION}

In Ukraine, at the state level, they are considering innovative development and prospects for its implementation in industrial enterprises in the next decade, in accordance with the Law of Ukraine "On Innovative Activity" and the National Report "Innovative Ukraine - 2020". In this regard, in order to get positive results from innovations and innovations, it is necessary that the susceptibility to innovation in the staff of industrial enterprises is high. This is what proves the relevance of the topic for today in the innovation activity of industrial enterprises and increasing their profitability and competitiveness.

It is commonly known that the personnel is the most important resource of innovative development of each company under current conditions. A well-organized Human Resource Management System is considered a key success factor. The aim of this research is the comparison of HRMS development levels in the world's leading companies and Ukrainian enterprises of industrial automation. Consequently, the task of the research is a comparative analysis of typical HRMS structures of both domestic and foreign enterprises with the aim of forming a strategy of HRMS development and the increase of innovative susceptibility of personnel.

The fellowship of human competition gift administration is single of the basal part of an efficaciously managed association. In the epoch of the knowledge-based compensatory, its distinction circles strategic as the strength of spryness inside this extent exclusively cinches the awareness of the company's aggressive assistance. Knowledge-based modes buoy be exclusively leading to peepee guarded this advantage [1], on the other hand they ballplayer further fragment a leading application in the cognitive semantics of discovering innovativeness [2], as blooming as to ante up to the betterment of the organizational completion [3].

It go on so whereas the fellowship remitted to in the firmament have reference to the administration of an organization's inside easy extent leading cap , i.e. the human competition capital and the knowledge it have. However, innovativeness is further requisite, and feasibly chiefly, as 
prizes the administration of these leading resources. Owing to such an act, improved effects buoy be expected [4].

\section{DEFINITIONS}

In view of the analysis of definitions, in our opinion the concept of "innovative susceptibility" (IS) may take the following form: Enterprise IS as a socio-economic category, which needs special attention from the point of view of both theoretical development and interrelated methodological approaches to its implementation, which are needed for the formation of tools for effective activity of innovative enterprise.

There is proposed the following wording: "innovative susceptibility of the personnel" (ISP) is the awareness of the personnel of the industrial enterprise of the possibilities of innovations and innovations, their perception within the given system and formation on this basis of the motivated readiness of the personnel of the enterprise for their realization.

Each employee should be "proactive": their behavior should depend on their own decisions, not on the surrounding conditions; everyone should be responsible for their decisions and actions that affect the activity of the enterprise.

In the research there is formulated and introduced the concept of "innovative susceptibility of Human Recourse Management System potential of industrial enterprise innovative activity" (IS HRSM potential IE IA) - a set of methods (raising) of staff awareness and its influence on the degree of efficiency of functions and subsystems. All this affects the efficiency of innovations and IA of industrial enterprises.

IS HRSM potential manifests itself in the innovative activity of the enterprise, including compliance with world standards of product standards, product update, and number of patents.

It is formulated definition "Human Recourse Management System" (HRMS) - a set of subsystems and functions that implement the methods, techniques, technologies of personnel within the organization and management structure of the company.

Also, it introduces the concept of "vector of innovative susceptibility of Human Recourse Management System" (vector IS HRMS), vector is an approach to orientation, a concept that allows for the formation of the potential of HRMS based on unidirectional target measures, as a factor in the systematic enhancement of IS personnel of IE in terms of ensuring its effectiveness in innovative markets, which contributes to the development of IE [12], [13], [14].

\section{THE PURPOSE OF THE RESEARCH}

The purpose of the study was to substantiate and develop theoretical and methodological approaches and practical recommendations that ensure the increase of innovative susceptibility of industrial enterprises personnel in the field of automation enterprise (AE). The aims are:
- to investigate the role of HRMS in the system of factors of IS personnel in the conditions of effective work of the enterprise in innovative markets.

- to analyze the system of factors of the HRMS, in view of the impact on raising the level of IS personnel.

- to propose a methodological approach to the analysis of the enterprise HRMS in order to ensure the activation of subsystems and functions to improve the IS personnel.

- to develop methodological approaches to assess the level of subsystems and functions of the HRMS, to propose a system for measuring its impact on the level of IS personnel.

- to propose an approach to increase the effectiveness of organizational and management support of the IP of the marketing system in the framework of the enterprise strategy for commercial service in the field of AE.

\section{METHODICAL SUGGESTIONS FOR FORMING AN} INSTRUMENT OF INCREASING THE INNOVATIVE SUSCEPTIBILITY OF INDUSTRIAL ENTERPRISE STAFF ON THE EXAMPLE OF INDUSTRY AUTOMATION

Based on the problems mentioned above, the key problems were highlighted, one of the problems is the lack of systematic planning of measures to improve the effectiveness of HRMS within the organizational management structure (OMS).

In the framework of the article it is suggested to consider a methodical approach which will allow to combine fragmentary provisions, tools, indexes into a single system.

This methodological approach is based on the intelligence vector - it is a targeted approach to target the organizational and economic conditions of enhancing the IS personnel of HRMS within the OMS based on increasing staff motivation.

Methodical approach to the analysis of the IS personnel level and the systems of its management of the HRMS: presented in Figure 1 in the form of a vector of development of IS personnel [5].

As we can see from the simplified scheme of vector of development of IS personnel (Figure 1) for the introduction of innovation (new products, new technologies, new strategies and concepts), we first need to analyze the status of IS personnel. At low IS $(\leq 0.5)$, staff need to develop actions to increase IS personnel, and implement them when we raise staff IP to high $(\geq 0.5)$ and, secondly, increase the IS of the entire industrial enterprise, these two we are assisted by HRMS and OMS processes, and then we will achieve positive results from innovations, which will bring IE to increase profits and increase competitiveness.

Before considering a methodical approach, it is necessary to understand the notion of IS potential of the HRSM IE IA, which, without enhancing the IS personnel, does not give positive results from the introduction of innovative innovations. 


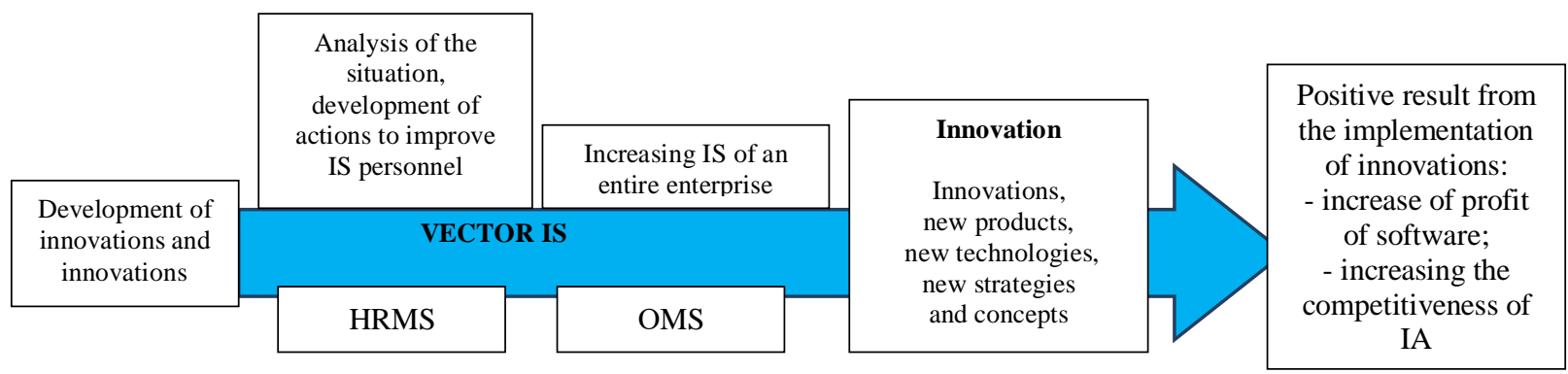

Fig. 1. Example of Simplified scheme of IS personnel development vector

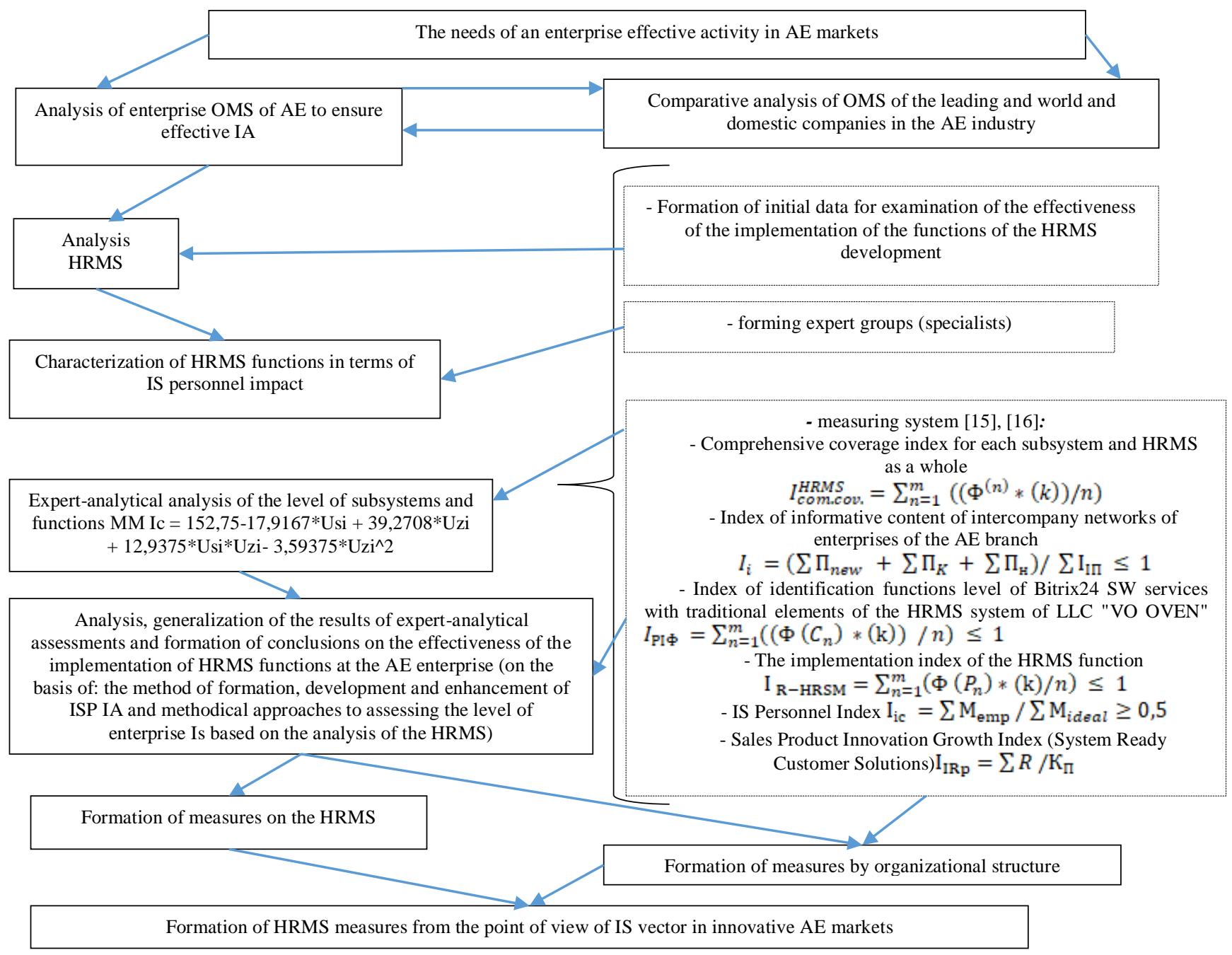

Fig. 2. Methodical approach to the formation of IS potential of the HRMS IA

A formalized methodological approach to increase the IS personnel in the form of regulatory proposals for AE subsector in the form of a block diagram is presented in Figure 2 [6], [7], [8], [9].

In our view, the methodological approach may have the following logic systematic logical structure presented in Figure 2 .

At table 1 shows measures to increase the IS personnel and examples for LLC "VO OVEN", based on the developed methodology.

\section{CONCLUSIONS}

The concept of vector IS HRMS potential is substantiated and formulated, which allows to formulate HRMS potential on the basis of unidirectional target measures, as a factor of systematic enhancement of IS personnel of IE in terms of ensuring its effectiveness in innovative markets. 
TABLE I. MEASURES TO INCREASE THE IS PERSONNEL AND EXAMPLES FOR LLC "VO OVEN"

\begin{tabular}{|c|l|l|}
\hline № & \multicolumn{1}{|c|}{ Measures to increase IS } & \multicolumn{1}{c|}{ Examples of measure in LLC "VO OVEN" } \\
\hline 1 & $\begin{array}{l}\text { Organization of training, personnel } \\
\text { certification }\end{array}$ & $\begin{array}{l}\text { Conducting sales training, enhancing personal efficiency, seminars and webinars on the } \\
\text { technical part of devices and ready-made solutions }\end{array}$ \\
\hline 2 & $\begin{array}{l}\text { Development of regulatory documents by } \\
\text { position }\end{array}$ & Developed job descriptions \\
\hline 3 & Organization of corporate events & $\begin{array}{l}\text { Conducting corporate seminars on ready-made solutions, interactions between divisions, } \\
\text { examples of industry decisions in competitors (experience) }\end{array}$ \\
\hline 4 & $\begin{array}{l}\text { Improvement of social-psychological } \\
\text { climate and corporate culture }\end{array}$ & $\begin{array}{l}\text { To enhance the team spirit and IS personnel of sports events (football matches, table tennis and } \\
\text { volleyball; kayaking; corporate events) }\end{array}$ \\
\hline 5 & Improving the efficiency of employees & $\begin{array}{l}\text { According to the results of the staff appraisal, measures have been developed for groups of } \\
\text { employees to improve the IS staff to increase their efficiency }\end{array}$ \\
\hline 6 & Business Process Optimization & $\begin{array}{l}\text { Taking over the experience of world leaders in AE, change in the structure, transition from } \\
\text { regional sales to industry, and preparation of ready-made industry decisions }\end{array}$ \\
\hline
\end{tabular}

A systematic set of factors of the HRMS, which influences the improvement of the IS personnel, in relation to $\mathrm{AE}$, which allows to provide organizationally managerial component of the work of the personnel on the basis of the development of measures that provide the appropriate organizational and managerial conditions of this enhancement.

That methodological approaches to assessing the level of subsystems of the HRMS functions have been further developed in terms of influencing the innovative susceptibility of personnel, which allows to develop targeted organizational and managerial measures for diagnostics of the condition and enhancement of individual IS of personal qualities of the personnel. The system for measuring the characteristics of the HRMS, which provide influence on the IS personnel, is improved, which allows to increase the efficiency of IE IA.

Based on the systematic approach to the justification and implementation of the vector of IS personnel, the approach to organizational and managerial support of innovative susceptibility of the marketing system of the enterprise to formulate a strategy for developing programs of measures to improve the business service in the field of $\mathrm{AE}$, which allows to improve sales efficiency conditions of innovative markets.

\section{REFERENCES}

[1] S. K. McEvily, B. Chakravarthy, "The persistence of knowledgebased advantage: an empirical test for product performance and technological knowledge", Strategic Manage. J., vol. 23(4), pp. 285305, 2002.

[2] C. Galunic, S. Rodan, "Resource recombination's in the firm: Knowledge structures and the potential for Schumpeterian innovation”, Strategic Manage. J, vol. 19(12), pp. 1193-1201, 1998.

[3] J. Wiklund, D. Shepherd, "Knowledge-based resources, entrepreneurial orientation, and the performance of small- and medium-sized businesses", Strategic Manage. J., vol. 24(13), pp. 1307-1314, 2003.

[4] M. W. Staniewski, "Management of Human Resources in the Aspect of Innovativeness", Contemp. Econ., pp. 84-91, 2011.

[5] Z. Bodrozic, P. S. Adle, "The Evolution of Management Models: A neo-Schumpeterian theory", Administrative Sci. Q., vol. 1(63), pp. 85129, 2017.
[6] D. Shin, M. J. Woodwark, and Y. Jung, "Employee voice human resource management practices and organizational innovative performance", $\quad$ Acad. 2017. https://doi.org/10.5465/ambpp.2017.10381abstract.

[7] J. H. Gittell, F. Pil, "Strategic relational human resource management: an emerging paradigm", Acad. Manage., 2017. https://doi.org/10.5465/ambpp.2017.14829symposium.

[8] O. Bokij, "Management "features by the personnel of companies in the countries of Western Europe, USA and Japan", 2018. [Online]. Available:

https://ru.osvita.ua/school/lessons_summary/edu_technology/28465/. Accessed on: July 24, 2019.

[9] "Market of industrial automation", Merchant. Business, 1993. [Online]. Available: http://www.kommersant.ru/doc.aspx?DocsID=55360. Accessed on: July $21,2019$.

[10] "Market of facilities of industrial automation and prospect of development", Automation and production, 2007. [Online]. Available: http://www.kipshop.ru/aip/index.php?id=364\&print=1\&no_cache=1 . Accessed on: July 24, 2019.

[11] P. V. Zhuravlev, M. N. Kulapov, and S. A. Sukharev, "World experience in a management by a personnel,; Monograph, econ. acad., Ekaterinburg, Russia, 1998.

[12] V. G. Dyuzhev, O. I. Boichenko, "Increase of innovative favourableness of personnel of commercial service of enterprises industrially automation", Announcer NTU "Kharkiv polytechnic institute", econ. sci., vol. 45 (1266), pp. 42-46, 2017. [in Ukrainian].

[13] V. G. Dyuzhev, O. I. Boichenko, "Innovative susceptibility of the market for industry electric power engineering", Electron. Sci. J. East. Europe: econ., bus. and manage., vol. 1(12), pp. 107-111, 2018. [in Ukrainian].

[14] V. G. Dyuzhev, "Forming of innovative directed control system by the personnel of enterprises and organizations", in 5th Int. sci. conf. "World economy of XXI century: modern tendencies of prospect of development", Lviv, 2011, pp. 69-71. [in Ukrainian].

[15] V. Babenko, V. Sidorov, Y. Koniaieva, and L. Kysliuk, "Features and prospects of scientific and technical cooperation in the field of nonconventional renewable energy", Global J. Environ. Sci. Manage., vol. 5, Special issue, pp. 105-112, 2019. doi: 10.22034/gjesm.2019.SI.12

[16] V. Babenko, I. Perevozova, O. Mandych, T. Kvyatko, O. Maliy, and I. Mykolenko, "Features and prospects of scientific and technical cooperation in the field of non-conventional renewable energy", Global J. Environ. Sci. Manage., vol. 5, Special issue, pp. 172-179, 2019. doi: $10.22034 /$ gjesm.2019.SI.19 